\title{
Uncertainties in the path to 2030: Increasing trends of under-five mortality in the aftermath of Millennium Development Goal in Eastern Ethiopia
}

\author{
Merga Dheresa ${ }^{1,2}$, \\ Hirbo Shore Roba ${ }^{3}$, \\ Gamachis Daraje $e^{2,4}$, \\ Mesfin Abebe ${ }^{2}$, Abera \\ Kenay Tura ${ }^{1,5}$, Tesfaye \\ Assebe Yadeta ${ }^{1}$, Yadeta \\ Dessie $^{3}$, Tariku Dingeta ${ }^{3}$ \\ ${ }^{1}$ School of Nursing and \\ Midwifery, College of Health \\ and Medical Sciences, \\ Haramaya University, Harar, \\ Ethiopia \\ ${ }^{2}$ Hararghe Health and \\ Demographic Surveillance \\ Systems, Harar, Ethiopia \\ ${ }^{3}$ School of Public Health, \\ College of Health and Medical \\ Sciences, Haramaya University, \\ Harar, Ethiopia \\ ${ }^{4}$ Department of statistics, \\ College of Computing and \\ Informatics, Haramaya \\ University \\ ${ }^{5}$ Department of Obstetrics \\ and Gynaecology, University \\ Medical Centre Groningen, \\ University of Groningen, the \\ Netherlands
}

\section{Correspondence to:}

Tariku Dingeta PhD

School of Public Health

College of Health and Medical

Sciences

Haramaya University

P.O.B. 235

Harar

Ethiopia

tarikuud@gmail.com
Background Although Ethiopia was applauded for achieving the Millennium Development Goal (MDG) target of reducing child mortality, whether the gains sustained beyond the MDG era was rarely studied. In this study, we reported the trends and determinants of under-five mortality (U5M) from 2015 to 2020 in a population based cohort under the Kersa Health and Demographic Surveillance System (HDSS), eastern Ethiopia.

Methods We followed pregnant women and their pregnancy outcomes from 2015 to 2020. Each year, data related to death and live births among the follow up population was retrieved. Automated verbal autopsy (InterVA-4) was used to assign the cause of death and Stata 14 was used for analysis. U5M rate was calculated as death among under five children divided by all live births during the study period and described per 1000 live births along with 95\% Confidence Interval (CI). A multivariable Cox proportional regression model was used to identify determinant of U5M using adjusted hazard ratio (AHR). Finally, $P$ value $<0.05$ was considered for declaring statistically significant association.

Results From January 2015 to December 2020, a total of 28870 live births were registered under the Kersa HDSS, of whom 1335 died before their fifth birthday. The overall U5M rate was 46.3 per 1000 live births $(95 \%$ confidence interval $(\mathrm{CI})=43.79-48.79)$, with significant increase from 27.9 in 2015 to 54.7 in $2020(P<0.041)$. Diarrheal diseases, acute respiratory tract infection including pneumonia, meningitis and encephalitis, and HIV related deaths were the leading causes of U5M. The hazard of death was higher among children born to poor household (AHR $=1.52 ; 95 \% \mathrm{CI}=1.27-1.81$ ), rural residents $(\mathrm{AHR}=6.0 ; 95 \% \mathrm{CI}=3.65-9.91)$, born to adolescent mothers (AHR $=1.41 ; 95 \%$ $\mathrm{CI}=1.02-1.95)$, whose mother didn't receive antenatal care $(\mathrm{AHR}=1.43 ; 95 \% \mathrm{CI}=1.21$ 1.69), were born preterm $(A H R=14.1 ; 95 \% C I=9.96-19.89)$ and had low birth-weight $(\mathrm{AHR}=1.74 ; 95 \% \mathrm{CI}=1.39-2.18)$.

Conclusion We found high level of U5M rate with an increasing trend in the aftermath of the praised MDG4 achievement. Achieving the ambitious U5M of 25 per 1000 live births by 2030 requires addressing diarrheal disease, and respiratory tract infections, and HIV/AIDS. Reasons behind the persistent increase over the study period require further inquiry.

Over the last three decades, substantial global progress has been made in reducing under-five mortality rate (U5MR) by 59\%, from 12.6 million in 1990 to 5.2 million in 2019. However, sub-Saharan Africa and Central and Southern Asia which are home to only $52 \%$ of the under-five population account for more than $80 \%$ of the 5.2 million under-five mortality (U5M) in 2019 [1,2]. For example, half of all the U5M in 2019 occurred in just five countries: Nigeria, India, Pakistan, the Democratic Republic of the Congo, and Ethiopia. In sub-Saharan 
Africa, one in every 13 children dies before reaching their fifth birthday [1]. Although Ethiopia is one of the countries which achieved the millennium development goal (MDG) targets of reducing U5M by two-third, the country is still home to high burden of U5M in Africa (third) and globally (tenth). Achieving the Sustainable Development Goals (SDG) 3.2.1 target of U5M rate to 25 per 1000 live births by 2030 requires understanding of the trends and determinants of mortality for designing appropriate interventions [3].

Moreover, the gains in reducing the U5MR were not equitable between and within regions. For example, the U5MR in Ethiopia in 2019 ranged from 29 in Addis Ababa to 74 per 1000 live births in Afar Region [4]. This inequity gap remains a challenge to achieve SDG targets, specifically among more marginal populations and rural settings [5]. A study by Nick et al. showed that the key factors to meet SDG targets at the national level are political commitment, financial support, and medical advances [6]. Recent analyses of the Ethiopian Demographic and Health Survey (DHS) 2016 data showed that several socio-demographic characteristics, access and quality of maternal health care services, infections, birth interval, and breastfeeding conditions were the major predictors of U5M [7-9]. These factors may not have similar effects given that there are substantial regional and sub-regional variations.

Health and demographic surveillance systems (HDSS) emerged as the best source of representative data for evidence generation, especially in rural settings and countries with no (weak) vital registration systems. The importance HDSS in responding to public health problems have been evident with the emergence of several DSS sites since the establishment of the first HDSS site - MATLAB - in 1966 [10]. Unlike facility-based studies or Demographic and Health Surveys, HDSS provides longitudinal data of a known and stable target population that enable us to understand trends and changes in the magnitude of determinants of mortality for tailored interventions. Unfortunately, studies in Ethiopia mainly used DHS data and provide a one-time estimate of U5MR than overtime changes with little information regarding the cause of death. Others are facility-based studies with limited applicability due to lack of appropriate denominators and being limited to urban centers. Hence, there is heightened need for more evidence that can show the change of U5MR over time and the major cause of deaths. Therefore, this study was intended to identify trends and causes of U5M in Kersa HDSS from 2015 to 2020.

\section{METHODS}

We used data from the ongoing Kersa HDSS, an HDSS affiliated with the College of Health and Medical Sciences, Haramaya University, eastern Ethiopia. Kersa HDSS is composed of two HDSS sites covering rural and urban settings: Kersa District and Harar Town. Kersa HDSS, established in 2007 in 12 kebeles (smallest administrative units in Ethiopia with 1500 average households) and added another 12 kebeles in 2015, was a predominantly rural HDSS [11]. In 2012, the HDSS field site was extended to Harar Town, a predominantly urban HDSS, covering six kebeles. Similarly, the Harar HDSS doubled its coverage to include 12 kebeles in total in 2015. Hence, Kersa HDSS covers 36 kebeles: 24 rural and 12 urban kebeles with a total population of 197268 in 41056 households [12]. All individuals who are living in HDSS were visited twice a year and individual updates are recorded and entered into the database system. The data was retrieved from all data generated from 2015 to 2020 as part of the routine HDSS data, including verbal autopsy data for all deaths during the same period. From a total of 29719 birth outcomes during the study period, 406 were miscarriage/ abortion and 436 were stillbirth. Thus, we followed 28870 live births in the HDSS during the study period (Figure 1).

\section{Study design and population}

Kersa HDSS is an open dynamic cohort designed to capture longitudinal records of health and demographic data to monitor vital events - births, deaths, and migration in a stable population at regular intervals - and updates relevant changes biannually [12]. Data were collected using ODK by well-trained regular HDSS staffs through face-to-face interview. Field

Figure 1. Flowchart of pregnancy observation and under-five deaths from 2015 to 2020 in Kersa HDSS, Eastern Ethiopia. 
nates, consistency, and validity of the response before it was sent to the Open HDSS database. If supervisors found a data quality problem, the data collectors were redeployed for correction under direct supervision. All collected data was temporarily stored on ODK aggregate. Then, the data manager reviewed the quality of data in ODK and migrated the data from temporary storage to the final Open HDSS database.

In this study, we followed pregnant women and respective pregnancy outcomes from 2015 to 2020. Data related to deaths and live births among the follow up population was retrieved for each year together with socio-demographic characteristics, household information, prenatal cares, obstetric characteristics, and child health conditions from birth to outcome of event (death) or censored (out migrated and alive). In addition, verbal autopsy was performed for each death through interview of the mother or the closest family member within 45 days of death of the child as described elsewhere [13]. Then, the verbal autopsy information was transferred to the automated verbal autopsy (InterVA-4) algorithm for assigning cause of deaths [14].

\section{Measurement and variables}

Women who gave birth were interviewed about outcome of their pregnancy (live births, stillbirth, or miscarriage) or any deaths of household members every six months. If death was reported, detailed information regarding the age of the deceased, date of death, sex, perceived cause of death, and place of death was collected through redeployment of data collectors using the standard World Health Organization verbal autopsy questionnaire $[15,16]$. The outcome variable was then categorized as 'death' or 'alive'. Death was assigned "1", and alive (censored) was a "0". Socio-demographic factors (place of residence, education status of mother, wealth index), maternal factors (age at first birth), and obstetrics factors (parity, place of delivery, ANC visits), child related factors (birth size, estimated gestation, and sex) were considered as explanatory variables for the U5M.

\section{Ethical considerations}

Kersa HDSS has obtained ethical clearance from the Science and Technology Minster of the Federal Democratic Republic of Ethiopia national ethical review committee (Ref No. EPHA/OG/1861/15) and the Institutional Health Research Ethical Review Committee (IHRERC) of College of Health and Medical Sciences, Haramaya University (Ref No and IHRERC/271/2014). Anonymity of data was maintained throughout the research process. All study participants gave informed written consent before inclusion into the HDSS.

\section{Data management and statistical analysis}

Data captured using ODK was exported to Stata 14 (Stata Corp 2015, College Station, TX) for analysis. U5MR was calculated as the death of a child during the first five years of life from all the live births during the same period and expressed per 1000 live births. Neonatal mortality rate was also calculated by neonatal death from all livebirths during the study period per 1000 live births. Kaplan-Meier survival curve was used to show patterns of death in 5 years, and a log-rank test was used to compare the survival curves among independent variables. Multivariable Cox proportional regression model, adjusted for socio-demographic characteristics (maternal education, and residence), reproductive and maternal health variables (parity, receive antenatal care, place of delivery, age at first birth childbirth), neonate related variables (birth weight, gestational age, and sex of newborn) was fitted to identify predictor variables. We consider the tests of equality across strata to include the predictor in the final model. For the categorical variables we used the log-rank test of equality across strata, and for the continuous variables we used a univariate Cox proportional hazard regression model. We consider the predictors if the test has a $P$ value of $<0.25$. Moreover, we checked proportionality assumption by including time-dependent covariates in the model. The results were reported using adjusted hazard ratio (AHR) with $95 \%$ confidence interval (CI). We checked multi-collinearity using variance inflation factors (VIF). We exclude gravidity from the model for it has collinearity with parity $(\mathrm{VIF}=10.41)$. In the multivariable analysis, variables having $P$ value $<0.05$ were considered as significant predictors of mortality.

\section{RESULTS}

\section{Socio-demographic characteristics}

From 2015 to 2020, we followed 19685 pregnant women and 29719 birth outcomes: 28870 livebirths, 413 miscarriage/abortion, and 436 stillbirths. Majority of the women were rural residents (23714; 82.1\%), older than 24 years $(20583 ; 72 \%)$, and were housewives (22 688; 78.8\%) (Table 1 ). 
Table 1. Characteristics of study participants in Kersa HDSS from 2015 to 2020, eastern Ethiopia

\begin{tabular}{lcc} 
VARIABLES & FREQUENCY & $\%$ \\
Residence $(\mathrm{n}=28870):$ & 5156 & 17.86 \\
\hline Harar Town & 23714 & 82.14 \\
\hline Kersa & & \\
\hline Mother age $(\mathrm{n}=28870):$ & 2031 & 7.10 \\
\hline $12-19$ & 5993 & 20.95 \\
\hline $20-24$ & 14959 & 52.29 \\
\hline $25-35$ & 5624 & 19.66 \\
\hline $35-49$ & & \\
\hline Ethnicity $(\mathrm{n}=28776):$ & 25409 & 88.30 \\
\hline Oromo & 2089 & 7.26 \\
\hline Amhara & 1278 & 4.44 \\
\hline Other & & 38.94 \\
\hline Educational status $(\mathrm{n}=28870):$ & 11241 & 1.79 \\
\hline Literate & 518 & 59.27 \\
\hline Read and or write & 17111 & \\
\hline Neither read nor write & & 78.81 \\
\hline Occupation $(\mathrm{n}=28790):$ & 22688 & 2.16 \\
\hline Housewife & 622 & 3.28 \\
\hline Daily laborer & 943 & 32.37 \\
\hline Merchant & 3561 & 31.85 \\
\hline Unemployed & 976 & \\
\hline Paid employer & 9438 & \\
\hline Wealth index $(\mathrm{n}=27775):$ & 9490 & \\
\hline Poor & 8847 & \\
\hline Middle & & \\
\hline Rich & & \\
\hline
\end{tabular}

\begin{tabular}{|c|c|c|}
\hline VARIABLES & FrEQUENCY & $\%$ \\
\hline \multicolumn{3}{|c|}{ Age at first child birth $(\mathrm{n}=28801)$ : } \\
\hline Less than 20 years & 17446 & 60.57 \\
\hline 20 years or older & 11355 & 39.43 \\
\hline \multicolumn{3}{|l|}{ ANC $(n=28870):$} \\
\hline Yes & 13343 & 46.22 \\
\hline No & 15527 & 53.78 \\
\hline \multicolumn{3}{|c|}{ Place of child birth $(n=28870)$ : } \\
\hline Home & 16644 & 57.65 \\
\hline Health facility & 12226 & 42.35 \\
\hline \multicolumn{3}{|c|}{ Birth attendant $(n=28869)$ : } \\
\hline TBAs & 12850 & 44.51 \\
\hline Health professional & 11968 & 41.46 \\
\hline Relative/ neighbors & 4051 & 14.03 \\
\hline \multicolumn{3}{|c|}{ Term of pregnancy $(n=28844)$ : } \\
\hline Term & 27021 & 93.68 \\
\hline Preterm & 286 & 0.99 \\
\hline Post-term & 1537 & 5.33 \\
\hline \multicolumn{3}{|c|}{ Birth weight $(\mathrm{n}=28651)$ : } \\
\hline Low & 2212 & 7.72 \\
\hline Normal & 23316 & 81.38 \\
\hline Big & 3123 & 10.90 \\
\hline \multicolumn{3}{|c|}{ Gender of child $(n=28870)$ : } \\
\hline Female & 13599 & 47.10 \\
\hline Male & 15271 & 52.90 \\
\hline
\end{tabular}

TBA - traditional birth attendants HDSS - Health and Demographic Surveillance System

Table 2. Under five mortality rates from 2015-2020 in Kersa HDSS Eastern Ethiopia

\begin{tabular}{cccc} 
YeAR & LIVE BIRTHS & UNDER-FIVE DEATH & U5MR/1000 LB (95\% CI) \\
2015 & 3906 & 109 & $27.91(29.13-33.66)$ \\
\hline 2016 & 4785 & 212 & $44.31(38.54-50.68)$ \\
\hline 2017 & 5422 & 213 & $39.28(34.18-44.92)$ \\
\hline 2018 & 5502 & 241 & $43.80(38.44-49.69)$ \\
\hline 2019 & 4560 & 303 & $66.44(59.17-74.36)$ \\
\hline 2020 & 4695 & 257 & $54.74(48.25-61.85)$ \\
\hline Overall & 28870 & 1335 & $46.24(43.79-48.79)$ \\
\hline
\end{tabular}

U5MR - under-five mortality rate, LB - live births, CI - confidence interval

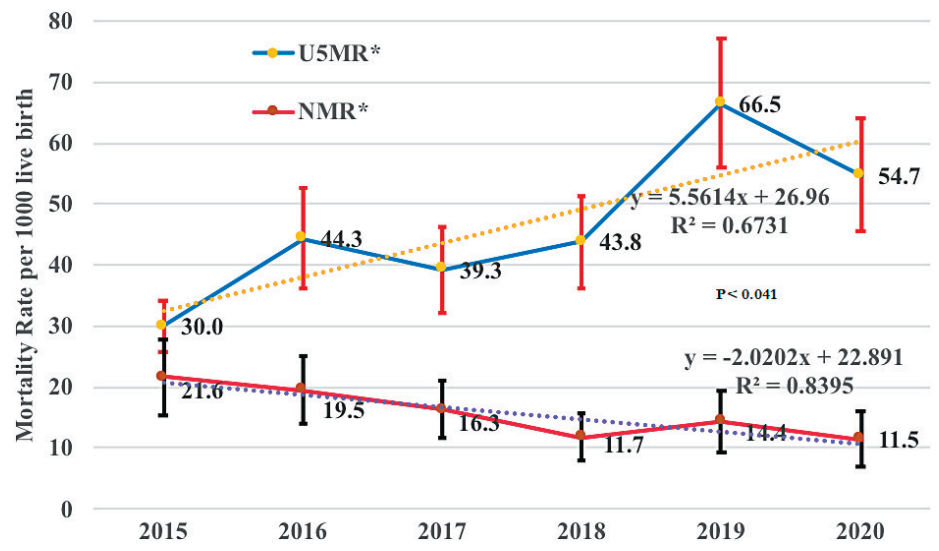

Figure 2. Trends of neonatal and under 5 mortality rates per 1000 live births in Kersa HDSS, eastern Ethiopia $(n=1335)$. U5MR - under-five mortality rate, NMR - neonatal mortality rate.

\section{Trend of under-five mortality}

A total of 1335 children died before their fifth birthday. More than a third $(447 ; 33.5 \%)$ of the deaths were neonates making the NMR 46.3 per 1000 live births. Majority of the deaths occurred at home (80\%; 95\% CI: 78\%-82\%). The overall U5MR was 46.3 per 1000 live births (95\% CI; 43.79-48.79). The annual mortality rate significantly increased from 27.9 per 1000 live births in 2015 to 54.7 per 1000 live birth in $2020(P<0.041)$. The highest $(66.4$ per 1000 live births) U5MR was in 2019 (Table 2). In contrast to the trend of under-five mortality rate, the neonatal death rate showed decreasing trend $(P<0.04)$ (Figure 2).

\section{Cause of under-five mortality}

Acute respiratory tract infection including pneumonia, diarrheal diseases and severe malnutrition were among the leading causes of death each year (Figure 3). Overall, diarrheal diseases, acute respiratory tract infection including pneumonia, meningitis and encephalitis, HIV-related deaths and severe malnutrition were the leading causes of death and attributed to more than for $50 \%$ of deaths (Figure 4).

\section{Determinants of under-five mortality}

Mortality was higher among children born to poor wealth index household (AHR $=1.52 ; 95 \% \mathrm{CI}=1.27$ - 


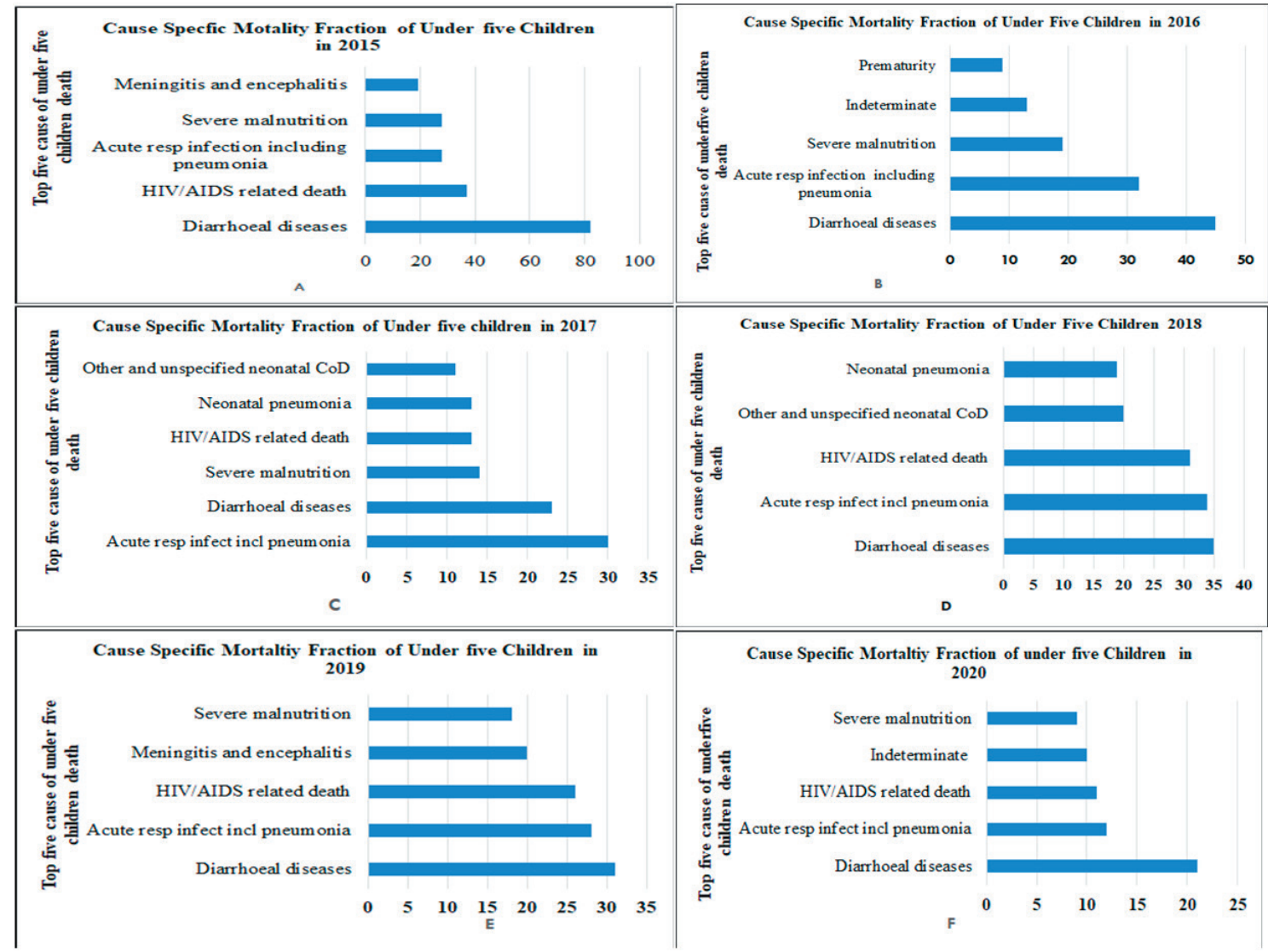

Figure 3. Cause-specific mortality fraction by year among under five children mortality in Kersa HDSS, eastern Ethiopia. COD - cause of death.

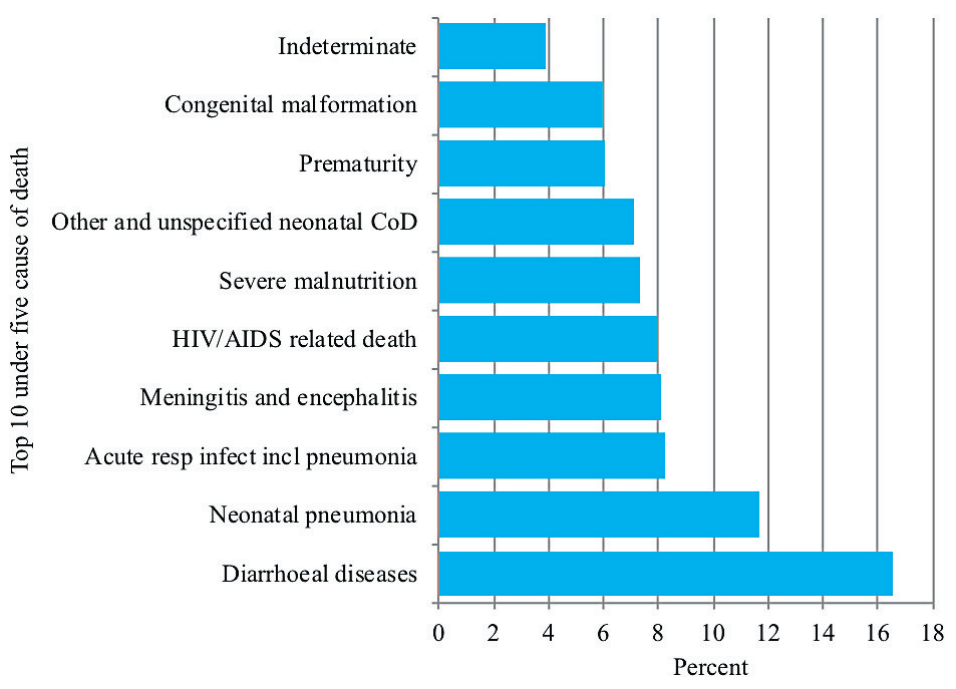

Figure 4. Cause-specific mortality fraction among under five mortality in Kersa HDSS, eastern Ethiopia, 2021. COD - cause of death.
1.81), rural residents $(A H R=6.0 ; 95 \% C I=3.65$ 9.91), born to adolescent mothers ( $A H R=1.41,95 \%$ $\mathrm{CI}=1.02-1.95)$, and whose mother never attended ANC $(A H R=1.43,95 \% C I=1.21-1.69)$. In addition, mortality was higher among both preterm $(\mathrm{AHR}=14.1 ; 95 \% \mathrm{CI}=9.96-19.89)$ and post term children $(\mathrm{AHR}=1.40 ; 95 \% \mathrm{CI}=1.03-1.90)$ compared to term children. Low birthweight $(\mathrm{AHR}=1.74,95 \%$ $\mathrm{CI}=1.39-2.18)$ and big birthweight $(\mathrm{AHR}=1.37,95 \%$ $\mathrm{CI}=1.05-1.79)$ were also associated with higher likelihood of early death compared normal birthweight (Table 3).

\section{DISCUSSION}

This study assessed the post-MDG trends, determinants and causes of U5M in a population-based study using verbal autopsy data in eastern Ethiopia. We found that, from 2015 to 2020, U5MR significantly increased while, NMR significantly decreased during the same period. Diarrheal diseases, acute respiratory tract infection including pneumonia, meningitis and encephalitis, HIV-related deaths and severe malnutrition were the leading causes of U5M. U5M was more likely among children born in low economic status households, whose mother never attended ANC, rural residents, born to adolescent mother, preterm and had low birthweight.

Overall, Ethiopia is still among the country with the highest U5MR in Africa [17-19]. Despite the slight reduction in neonatal mortality, which would give hope to the likelihood to achieve the SDG targets, failure to reduce 
Table 3. Determinants of under-five mortality in Kersa DHSS eastern Ethiopia

\begin{tabular}{|c|c|c|}
\hline VARIABLE & CHR (95\% Cl) & AHR (95\% CI) \\
\hline \multicolumn{3}{|l|}{ Residence: } \\
\hline Harar Town & 1 & 1 \\
\hline Kersa District & $6.82(5.03-9.24)^{*}$ & $6.01(3.65-9.91)^{*}$ \\
\hline \multicolumn{3}{|l|}{ Educational status: } \\
\hline Literate & 1 & 1 \\
\hline Read and/or write & $2.01(1.36-2.96)$ & $1.48(0.93-2.35)$ \\
\hline Neither read nor write & $2.10(1.85-2.38)$ & $1.17(0.98-1.39)$ \\
\hline \multicolumn{3}{|l|}{ Occupation: } \\
\hline House wife & 1 & 1 \\
\hline Daily laborer & $0.66(0.43-1.01)$ & $1.04(0.62-1.75)$ \\
\hline Merchant & $0.36(0.23-0.58)$ & $0.74(0.32-1.70)$ \\
\hline Unemployed & $0.86(0.73-1.02)$ & $0.83(0.65-1.06)$ \\
\hline Paid employee & $0.078(0.02-0.21)$ & $0.48(0.15-1.57)$ \\
\hline \multicolumn{3}{|l|}{ Wealth index: } \\
\hline Poor & $1.55(1.35-1.79)^{*}$ & $1.52(1.27-1.81)^{*}$ \\
\hline Middle & $1.41(1.23-1.63)^{*}$ & $1.27(1.06-1.53)^{*}$ \\
\hline Reach & 1 & 1 \\
\hline \multicolumn{3}{|l|}{ Age at first child birth: } \\
\hline Less than 20 years & $1.40(1.25-1.57)^{*}$ & $1.05(0.90-1.23)$ \\
\hline 20 years and above & 1 & 1 \\
\hline \multicolumn{3}{|l|}{ Mother's age (years): } \\
\hline $12-19$ & $1.33(1.09-1.62)^{*}$ & $1.41(1.02-1.95)^{*}$ \\
\hline $20-24$ & $0.89(0.77-1.03)$ & $0.87(0.69-1.08)$ \\
\hline $25-35$ & 1 & 1 \\
\hline $35-49$ & $1.28(1.12-1.47)^{*}$ & $1.03(0.85-1.26)$ \\
\hline
\end{tabular}

\begin{tabular}{|c|c|c|}
\hline VARIABLE & CHR (95\% Cl) & AHR (95\% Cl) \\
\hline \multicolumn{3}{|c|}{ Attended ANC: } \\
\hline Yes & 1 & 1 \\
\hline No & $1.29(1.12-1.47)$ & $1.43(1.21-1.69)^{*}$ \\
\hline \multicolumn{3}{|l|}{ Gravidity: } \\
\hline 1 & 1 & 1 \\
\hline $2-4$ & $0.93(0.80-1.09)$ & $0.99(0.77-1.28)$ \\
\hline$\geq 5$ & $1.41(1.21-1.41)^{*}$ & $0.78(0.54-1.14)$ \\
\hline \multicolumn{3}{|c|}{ Term of pregnancy: } \\
\hline Term & 1 & 1 \\
\hline Preterm & $7.15(5.71-8.95)^{*}$ & $14.08(9.96-19.89) *$ \\
\hline Post term & $1.46(1.19-1.79)^{*}$ & $1.40(1.03-1.90)^{*}$ \\
\hline \multicolumn{3}{|c|}{ Birth weight: } \\
\hline Low & $1.93(1.65-2.25)^{*}$ & $1.74(1.39-2.18)^{*}$ \\
\hline Normal & 1 & 1 \\
\hline Big & $0.73(0.59-0.89)^{*}$ & $1.37(1.05-1.79)^{*}$ \\
\hline \multicolumn{3}{|c|}{ Sex of the child: } \\
\hline Female & 1 & 1 \\
\hline Male & $1.07(0.96-1.19)$ & $1.09(0.95-1.25)$ \\
\hline
\end{tabular}

or the increasing trend in overall U5MR requires strong multifaceted and accelerated interventions. One unanticipated finding was the highest U5MR observed in 2019. This could be attributed to the instability in the study area which caused repeated closure of roads to health facilities throughout the year. Generally, this study based on the more reliable and repeated data source clearly pointed out the challenges ahead in Ethiopia to achieve the SDG targets.

Our findings is consistent with the 2019 Ethiopian Mini DHS, which reported U5MR of 55 per 1000 live births [20]. The recent United Nations Inter-agency Group for Child under five mortality estimation also showed high U5M in Ethiopia and highlighted the challenges ahead to meet the SDG goal in this regards [21]. A study which assessed trends of U5M in 31 sub-Saharan African countries estimated the Ethiopian U5MR to be 59 per 1000 live births, classifying Ethiopia among countries with slowest pace of child mortality reduction [17]. Similar finding was also observed in a study conducted in Arbaminch HDSS in Ethiopia which reported 43 death per 1000 live birth [22]. However, the U5MR in this study is slightly higher than the reported 35.6 deaths per 1000 live births in study conducted in Kilite-Awlaelo HDSS site, Tigray Ethiopia [23].

Consistent with other studies, our study showed that many children are dying from communicable diseases: diarrheal diseases and lower respiratory infections [24]. Although the burden of diarrhea among under-five children was reported to decline remarkably in the last two decades $[25,26]$, this does not appear to be the case in this study. One of the issues that emerge from this finding is the major decline in child mortality as well diarrheal disease cause-specific mortality from 2000 to 2016 in Ethiopia is stacked [27]. Reduction of follow-up and support for health extension workers, repeated closure of roads as well as health facilities, and supply chain disruption such as Oral Rehydration Solution (ORS), vaccine, and other lifesaving drugs due to the continued instability in the country in the last few years might explain this observation. Therefore, strengthening and scaling up of behavioral change about importance of personal hygiene and environmental sanitation, child immunization, and strengthening health care seeking is required to reduce the burden of morbidity and mortality attributed to diarrheal diseases.

Children born to adolescent mothers had higher hazard of mortality compared to those 25-34 years old. This is in accord with recent studies indicating up to 4 times increased of risk of death of children born to adolescent mothers compared to those born to young adult mothers $[28,29]$. Given that more than six in ten women included in this study gave their first birth before 20 years of age, still an unexpectedly high proportion of 
rural Ethiopian girls are suffering from teenage pregnancy. The observed dramatically worsening survival of children born to adolescent mothers is likely attributed to combination of biological and social factors: poor reproductive maturity and low decision making power of the teens to access sexual and reproductive health services for themselves or their children [29]. There is, therefore, a definite need for reducing adolescent births and its complications as a strategy for addressing the problem of neonatal and child mortality through prevention of early marriage, and ensuring access to quality maternal health services, including use of contraception for delaying teen age pregnancy.

In this study, preterm and low birthweight children were found to be more at risk of dying before celebrating their fifth birthday compared to term birth and normal birth weight, respectively. Increasing risk of mortality with decrease in gestational age at delivery and low birthweight was previously reported [30-32]. Increased risk of death among preterm and low birthweight children born at home was reported due to lack of quality care and treatment for short and long-term health consequences such as hypothermia immediately after birth and in the first days of life [33]. Effect of increased mortality among low-birth-weight due to severe short- and long-term health consequences were also reported elsewhere [19].

The strength of this study was the fact that we followed large cohort of pregnant women from conception to five years after birth. The longitudinal nature of the study enabled us to explore the trends and changes overtime in a stable cohort. However, a number of important limitations should be considered. First, misclassification of cause of deaths using verbal autopsy could over or under-estimate some causes of deaths. In addition, data on cause of deaths was obtained from the closest family member compared to use of physician diagnosis in facility-based studies. This could be prone to bias related with recalling some of the circumstances surrounding the child death.

\section{CONCLUSION}

Against the odds, this study has identified high level of U5MR with noticeable increase in the aftermath of the celebrated MDG success. Despite the early praises for achieving the U5MR reduction as part of the millennium development goals project, this study highlights that Ethiopia is not on track to achieving the 2030 SDG target of U5MR of 25 per 1000 live births. Several factors, ranging from complacence to wide scale insecurity or the persistence of diarrheal diseases, could explain the reasons behind the increasing trends in the U5MR in this predominantly rural setting. As such, commitments to the 2030 targets should consider the multifaceted politico-economic challenges driving the increase in the trends.

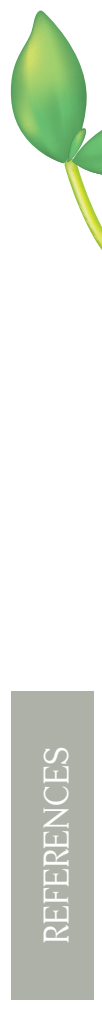

Acknowledgments: We would like to thank Haramaya University Kersa HDSS for sharing us the data for analysis. We gratefully acknowledge all data collectors, supervisors, data managers and data clerks for their contribution.

Availability of data: All essential data required for the conclusion are included in the study. The data is a property of Haramaya University and would not be made public due to ethical restrictions. However, additional data may be obtained from the HDSS following the institutional data request and sharing policy.

Funding: Hararghe HDSS is funded partly by CDC and Haramaya University. The funders have no role in the design, collection, analysis or interpretation of findings or the decision to publish.

Authorship contribution: All authors made substantial contributions acquisition of data, or analysis and interpretation of data; took part in drafting the article or revising it critically for important intellectual content; gave final approval of the version to be published; and agree to be accountable for all aspects of the work.

Competing interests: The authors completed the ICMJE Declaration of Interest Form (available upon request from the corresponding author), and declare no conflict of interest.

1 World Health Organization. Children: improving survival and well-being. Geneva: World Health Organization; 2020.

2 Burstein R, Henry NJ, Collison ML, Marczak LB, Sligar A, Watson S, et al. Mapping 123 million neonatal, infant and child deaths between 2000 and 2017. Nature. 2019;574:353-8. Medline:31619795 doi:10.1038/s41586-019-1545-0

3 Ethiopian Public Health Institute (EPHI) [Ethiopia] and ICF. Ethiopia Mini Demographic and Health Survey 2019: Final Report. Rockville, Maryland, USA: EPHI and ICF; 2021.

4 United Nations Inter-agency Group for Child Mortality Estimation (UNIGME). Levels \& Trends in Child Mortality: Report 2020, Estimates developed by the United Nations Inter-agency Group for Child Mortality Estimation. New York: United Nations Children's Fund; 2020. 
5 Assefa Y, Damme WV, Williams OD, Hill PS. Successes and challenges of the millennium development goals in Ethiopia: lessons for the sustainable development goals. BMJ Glob Health. 2017;2:e000318. Medline:29081999 doi:10.1136/bmjgh-2017-000318

6 Golding N, Burstein R, Longbottom J, Browne AJ, Fullman N, Osgood-Zimmerman A, et al. Mapping under-5 and neonatal mortality in Africa, 2000-15: a baseline analysis for the Sustainable Development Goals. Lancet. 2017;390:2171-82. Medline:28958464 doi:10.1016/S0140-6736(17)31758-0

7 Geremew BM, Gelaye KA, Melesse AW, Akalu TY, Baraki AG. Factors Affecting Under-Five Mortality in Ethiopia: A Multilevel Negative Binomial Model. Pediatric Health Med Ther. 2020;11:525-34. Medline:33408551 doi:10.2147/PHMT.S290715

8 Takele K, Zewotir T, Ndanguza D. Risk factors of morbidity among children under age five in Ethiopia. BMC Public Health. 2019;19:942. Medline:31307433 doi:10.1186/s12889-019-7273-4

9 Fenta SM, Fenta HM. Risk factors of child mortality in Ethiopia: Application of multilevel two-part model. PLoS One. 2020;15:e0237640. Medline:32804942 doi:10.1371/journal.pone.0237640

10 D'Souza S. A population laboratory for studying disease processes and mortality - the Demographic Surveillance System, Matlab Comilla, Bangladesh. Rural Demogr. 1981;8:29-51. Medline:12338517

11 Assefa N, Lakew Y, Belay B, Kedir H, Zelalem D, Baraki N, et al. Neonatal mortality and causes of death in Kersa Health and Demographic Surveillance System (Kersa HDSS), Ethiopia, 2008-2013. Matern Health Neonatol Perinatol. 2016;2:7. Medline:27437118 doi:10.1186/s40748-016-0035-8

12 Assefa N, Oljira L, Baraki N, Demena M, Zelalem D, Ashenafi W, et al. HDSS Profile: The Kersa Health and Demographic Surveillance System. Int J Epidemiol. 2016;45:94-101. Medline:26510420 doi:10.1093/ije/dyv284

13 Ashenafi W, Eshetu F, Assefa N, Oljira L, Dedefo M, Zelalem D, et al. Trend and causes of adult mortality in Kersa health and demographic surveillance system (Kersa HDSS), eastern Ethiopia: verbal autopsy method. Popul Health Metr. 2017;15:22. Medline:28666480 doi:10.1186/s12963-017-0144-2

14 Hazard RH, Buddhika MPK, Hart JD, Chowdhury HR, Firth S, Joshi R, et al. Automated verbal autopsy: from research to routine use in civil registration and vital statistics systems. BMC Med. 2020;18:60. Medline:32146903 doi:10.1186/s12916020-01520-1

15 World Health Organiation. Source Manual and guidelines for application and use of simplified WHO VA tool 2016v1-4-2. Geneva: WHO; 2016.

16 World Health Organization. 2012 WHO VErbal Autopsy Sample Questionnaire 3. Geneva: WHO; 2012.

17 Mejía-Guevara I, Zuo W, Bendavid E, Li N, Tuljapurkar S. Age distribution, trends, and forecasts of under-5 mortality in 31 sub-Saharan African countries: A modeling study. PLoS Med. 2019;16:e1002757. Medline:30861006 doi:10.1371/journal. pmed. 1002757

18 Agborndip E, Kadia BM, Ekaney DSM, Mbuagbaw LT, Obama MT, Atashili J. Under-Five Mortality in Buea Health District, Southwest Cameroon: Evidence from a Community-Based Birth Cohort Study of Rate, Causes, and Age-Specific Patterns. Int J Pediatr. 2020;2020:9605492. Medline:32426000 doi:10.1155/2020/9605492

19 Strong KL, Pedersen J, White Johansson E, Cao B, Diaz T, Guthold R, et al. Patterns and trends in causes of child and adolescent mortality 2000-2016: setting the scene for child health redesign. BMJ Glob Health. 2021;6:e004760. Medline:33731440 doi:10.1136/bmjgh-2020-004760

20 Ethiopian Public Health Institute E, Federal Ministry of Health F, Icf. Ethiopia Mini Demographic and Health Survey 2019. Addis Ababa, Ethiopia: EPHI/FMoH/ICF; 2021.

21 United N. Inter-agency, Group, for, Child,Mortality, Estimation, Subnational Under-five Mortality Estimates, 1990-2019: Estimates developed by the United Nations Inter-agency Group for Child Mortality Estimation. New York: United Nations Children's Fund; 2021

22 Shifa GT, Ahmed AA, Yalew AW. Early days of life are crucial for child survival in Gamo Gofa Zone, Southern Ethiopia: A community based study. BMC Pediatr. 2016;16:30. Medline:26946507 doi:10.1186/s12887-016-0568-z

23 Abraha HE, Belachew AB, Ebrahim MM, Tequare MH, Adhana MT, Assefa NE. Magnitude, trend, and causes of under-five mortality from Kilite-Awlaelo health demographic surveillance database, northern Ethiopia, 2009-2017. BMC Public Health. 2020;20:1465. Medline:32993625 doi:10.1186/s12889-020-09554-z

24 Wang H, Bhutta ZA, Coates MM, Coggeshall M, Dandona L, Diallo K, et al. Global, regional, national, and selected subnational levels of stillbirths, neonatal, infant, and under-5 mortality, 1980-2015: a systematic analysis for the Global Burden of Disease Study 2015. Lancet. 2016;388:1725-74. Medline:27733285 doi:10.1016/S0140-6736(16)31575-6

25 Mesfin Y. M A. Burden of Diarrheal Disease among under Five Children in Ethiopia, 2000-2016: Findings from the Global Health Estimates 2016. Health Sci J. 2021;1:801.

26 Misganaw A, Haregu TN, Deribe K, Tessema GA, Deribew A, Melaku YA, et al. National mortality burden due to communicable, non-communicable, and other diseases in Ethiopia, 1990-2015: findings from the Global Burden of Disease Study 2015. Popul Health Metr. 2017;15:29. Medline:28736507 doi:10.1186/s12963-017-0145-1

27 Negesse Y, Taddese AA, Negesse A, Ayele TA. Trends and determinants of diarrhea among under-five children in Ethiopia: cross-sectional study: multivariate decomposition and multilevel analysis based on Bayesian approach evidenced by EDHS 2000-2016 data. BMC Public Health. 2021;21:193. Medline:33482778 doi:10.1186/s12889-021-10191-3

28 Neal S, Channon AA, Chintsanya J. The impact of young maternal age at birth on neonatal mortality: Evidence from 45 low and middle income countries. PLoS One. 2018;13:e0195731. Medline:29791441 doi:10.1371/journal.pone.0195731

29 Noori N, Proctor JL, Efevbera Y, Oron AP. The Effect of Adolescent Pregnancy on Child Mortality in 46 Low- and Middle-Income Countries. medRxiv. 2021:2021.06.10.21258227. doi:10.1101/2021.06.10.21258227 
30 Dhaded SM, Somannavar MS, Moore JL, McClure EM, Vernekar SS, Yogeshkumar S, et al. Neonatal deaths in rural Karnataka, India 2014-2018: a prospective population-based observational study in a low-resource setting. Reprod Health. 2020;17:161. Medline:33256777 doi:10.1186/s12978-020-01014-6

31 Song P, Theodoratou E, Li X, Liu L, Chu Y, Black RE, et al. Causes of death in children younger than five years in China in 2015: an updated analysis. J Glob Health. 2016;6:020802. Medline:28028436 doi:10.7189/jogh.06.020802

32 Aguilera X, Delgado I, Icaza G, Apablaza M, Villanueva L, Castillo-Laborde C. Under five and infant mortality in Chile (1990-2016): Trends, disparities, and causes of death. PLoS One. 2020;15:e0239974. Medline:32997709 doi:10.1371/journal.pone.0239974

33 Muhe LM, McClure EM, Nigussie AK, Mekasha A, Worku B, Worku A, et al. Major causes of death in preterm infants in selected hospitals in Ethiopia (SIP): a prospective, cross-sectional, observational study. Lancet Glob Health. 2019;7:e1130-8. Medline:31303299 doi:10.1016/S2214-109X(19)30220-7 